\title{
Selecting Fog Harvesting Meshes for Environmental Conditioning Structures
}

\author{
L. Hadba, P. Mendonça, L.T. Silva, and M. A. Carvalho
}

\begin{abstract}
Fog harvesting is a technique used to collect water from the fog. This technique became widely used around the world due to the lack of fresh water, as fog harvesting is considered to represent an economical and a reliable source of water. On that sense, fog collecting methods are mostly implemented in areas that lack access to fresh water and is mostly used for agricultural purposes and, in some cases, also for providing clean drinking water. The basic idea of harvesting the fog was first developed by farmers when some types of adjoining cavities and containers were put around plants to collect water from humid air, after that those techniques were turned into fog harvesting structures. The introduction of fog harvesting techniques was accompanied with the introduction of new materials and different structures, providing a range of options in regards to the meshes and to the harvesting methods. In this paper, a practical and theoretical assessment of existing fog harvesting meshes is performed in order to characterize their economic and physical characteristics. The final objective is to provide information about their ability to perform in different conditions which is to be added to an environmental conditioning structure for exterior spaces.
\end{abstract}

Index Terms-Fog harvesting, meshes, embodied energy, pollution potential, environmental impact, economic impact.

\section{INTRODUCTION}

According to WHO, in 2019 around 785 million people lacked basic drinking water service, including 144 million people who mostly depend on surface water. Whereas globally it is estimated that about two thousand million people use a contaminated drinking source, it is estimated that about 485,000 diarrheal deaths per year are caused by contaminated drinking water. Furthermore, it is forecasted that by 2025 more than half of the world population would be living in a water stressed area. The lack of water affects all living creatures, thus the lack of clean water also affects the type of vegetation and the bio diversity in the area [1].

Fog harvesting is simply based on the physical principle that when humid air encounters a cold solid surface, the water molecules disposed in the air will adhere to that surface

Manuscript received March 10, 2020; revised October 20, 2020. This work has the financial support of 2C2T- Science Center of Textile Technology and the Project Lab2PT - Landscapes, Heritage and Territory laboratory - AUR/04509, with the financial support from FCT/MCTES through national funds (PIDDAC) and co-financing from the European Regional Development Fund (FEDER) POCI-01-0145-FEDER-007528 and POCI-01-0145-FEDER-007136, in the aim of the new partnership agreement PT2020 through COMPETE 2020 - Competitiveness and Internationalization Operational Program (POCI), and by national funds through the Foundation for Science and Technology of FCT-Portugal under the UID/CTM project / 000264

The authors are with the University of Minho, Portugal (e-mail: lujainhadba@gmail.com, 1silva@civil.uminho.pt,migcar@det.uminho.pt).
[2]. With water being an important source of life, it was noticed that some plants have the ability to collect dew in foggy climate to compensate for the lack of liquid water. Taking that into consideration, the last years witnessed the development of different techniques in the purpose of harvesting water from humid air. On Cape Verde, Oman, and Canary Island the farmers traditionally put containers under different species of trees to collect water dripping from the leaves on fogging periods [3]. While in Palestine, the idea of a fog-collecting structure became more concrete as the inhabitants used to build structures with adjoining cavities around their vines so the surrounding fog and mist could participate in the irrigation of their plants [4]. On the other hand, insects such as cicadas were noted to have the ability of removing water droplets from rain and fog though their wings, using the wing gradient surface of roughness and wettability to accumulate water, which later inspired the development of fog harvesting gradient wetting surfaces by caricaturing the structure of the wings [5].

The idea of developing a certain structure that provides a better water collection started with Schemenauer and Cereceda as the Standard Fog Collector (SFC) was suggested [6], later to be involved in recent projects such as the Warka Water towers and recent fog harvesting projects all around the world, [7]-[9]. A fog collector is generally composed by a frame that supports a section of mesh in a vertical plane. As for the mesh, it is normally exposed to the atmosphere where the foggy air could be pushed through the mesh by the wind, with the droplets being disposed to the mesh. They combine to form larger droplets that run down passing into the storage tank in the bottom.

Raschel mesh is the material that is mostly used in fog harvesting applications worldwide. The mesh is made of a food-safe polyethylene and should present a wire radius and a spacing ratio of the woven that makes it efficient in collecting water. On the other hand, in some areas, it is not possible to use the Raschel mesh in fog harvesting structure, due to the lack of the material. This paper explores the possibility of using different types of meshes, characterizing them in terms of economic cost, physical and chemical properties, as well as its environmental impact assessed in their positive and negative effects.

\section{Methodology}

The process of using the meshes for an environmental conditioning structure must take into consideration their functionality, but should be accompanied by an evaluation of the impact associated with its industrial production. The study was comprised of two approaches. In the first approach, depending on the materials and energy used for production, 
the environmental impacts were evaluated. Furthermore, their fog collection efficiency was analyzed using the Droplet Impact Models proposed by Langmuir and Blodgett [10], [11].

In the second approach, a laboratory analysis was performed on different meshes to specify their physical and chemical characteristics. The analysis will later include the experimental results from a fog harvesting structure set in Guimarães, Portugal, to test the ability of some selected meshes to collect water from fog.

\section{FIRST APPROACH}

\section{A. Environmental Conditioning Benefits of Fog Harvesting Meshes}

The meshes used in fog harvesting can have varied environmental impacts depending on their material and their physical appearance. The composition, thickness and weight of the meshes have important effects on their durability, maintenance and in their environmental characteristics, which are explored in this section.

Mesh physical parameters directly influence its ability to collect water. Shading coefficient (SC) represent the percentage of fabric area to the whole area of the mesh, whereas the remaining area in the mesh could be considered as the open area. Most of the meshes used in fog harvesting have a certain amount of open areas that could affect the mesh ability to allow wind to pass through the mesh thus enhancing or worsening the mesh ability to collect water. Whereas a greater value of SC could lead to a higher number of droplets to be disposed on the surface of the mesh due the interaction between the mesh and the droplets, a really high level of SC could lead to what is known as the shielding effect reducing the flow of the wind through the mesh [12]. The open areas in the meshes do not only affect its ability to collect water and filter the wind, but also affect their ability of providing shading and so, to protect them from heat. It was found that with more solar radiation passing through the mesh, higher is the operative temperature. To ensure a good protective effect, the mesh shading factor must be at least $50 \%$ [13]. The Raschel mesh is preferred to have a $35 \%$ shading coefficient to perform efficiently as a fog harvesting mesh. Other meshes are produced with different open areas percentages and shading factors. That, in some cases, enhances their ability to provide shading although affecting their water harvesting abilities due to the shielding effect, where, it is critical for the mesh to allow wind to pass through it to be able to capture water droplets deposited in the air. While larger percentage of open areas could increase its ability to capture fog, it may, however, decrease its ability to provide shading, (see Table I), (see Fig. 1).

Fog harvesting meshes, with their ability to collect fog, could help in some cases as the collection of fog could limit the number of toxins in the air. The meshes with higher ability of collecting water could provide improved air quality either by collecting toxic pollutants in the humid air, or by rainfall, which eventually washes off the pollutants on the mesh surface down to the collector. However, this could have an opposite effect on the water collected, as it will not meet the WHO standards, making the collected water not safe for human and other living beings' consumption. It was found that in the urban areas fog could be affected by the presence of industries' emissions, as higher levels of particles and heavy metals are found in the fog of those areas [14]. The ability to absorb toxins disposed on the air proved to be higher in urban areas compared to rural areas, as the fog in urban areas exhibit higher levels of total organic carbon, nitrate and sodium and as a result have a lower PH level [15].

Scientific literature is lacking studies on the physical and acoustical characteristics of polyester fiber materials. Some barriers could add polyester to its composition, as the ability of polyester to absorb noise pollution could be affected by its thickness, surface area and fiber size. Thus, the higher the open areas of the mesh the lower its ability to perform as a noise barrier. As presented in the study of Lin et al [16], it is noted on the first stages of the study that the mesh with higher open areas ratio has a lower sound absorption coefficient. On the other hand, PVC films could be added to the fabric as it could increase the fabric sound absorption at low and mid frequencies at the expense of higher frequencies [17]. It must be taken into consideration that fog harvesting meshes, if implemented alone, are not able to provide effective noise abatement due to the lack of thickness and the openings in the meshes' fabric which affect their noise absorption. Thus, the protection from nets alone to the noise is mostly psychological as they offer visual protection by blocking the noise source, thus reducing noise sensitivity.

\begin{tabular}{|c|c|c|c|}
\hline Name & Open Areas & $\begin{array}{l}\text { Thickness } \\
\text { (mm) }\end{array}$ & Composition \\
\hline PVCPE1 (A) & $41 \%$ & 0.78 & $\begin{array}{l}72 \% \text { PVC }-28 \% \\
\text { Polyester }\end{array}$ \\
\hline PVCPE6 (B) & $7.54 \%$ & 0.64 & $\begin{array}{l}57 \% \text { PVC }-43 \% \\
\text { Polyester }\end{array}$ \\
\hline PE2 (C) & $23.5 \%$ & 1.31 & Polyethylene \\
\hline JE (D) & $49.2 \%$ & 1.91 & Woven Jute \\
\hline
\end{tabular}

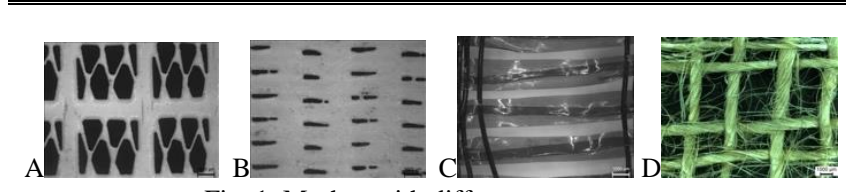

Fig. 1. Meshes with different open areas.

\section{B. Environmental Impact}

The environmental impact of the meshes could be linked to their harmful effect on the environment related with the pollution emitted during production process and after waste disposal. In the present study, most of the meshes are composed of polyester with PVC coating. Production of PVC emits chlorine gas, ethylene, dioxin, vinyl chloride, the solvent dichloretane, mercury and other damaging substances, thus, leading to serious health problems, especially for workers directly exposed to the production process if not enough cautions are taken. PVC is considered to be the largest source of chlorine in waste products. When burnt, it can form concentrated hydrochloric acid and dioxin, among other gases such as carbon monoxide $\mathrm{CO}$, carbon dioxide $\mathrm{CO}_{2}$, methane $\mathrm{CH}_{4}$, barium $\mathrm{Ba}$ and cadmium $\mathrm{Cd}$ [18]. On the other hand, polyester can produce styrene and dichloromethane during its production, whereas if burned it emits $\mathrm{CO}, \mathrm{CO}_{2}$, benzene, styrene, formaldehyde, which 
could be considered harmful in high concentrations.

Other meshes similar to Raschel mesh are made from polyethylene. Polyethylene is not easy to decompose; however, it could be burned without emitting dangerous gases [18]. Furthermore, some meshes are also composed of Nylon, one of the most commonly used polyamides (PA). The production of Nylon emits carbon dioxide, nitrous oxide, Sulphur dioxide and methane among other gases. Nylon could be produced in many forms such as Nylon 6 and Nylon 6.6, where Nylon 6 is produced from caprolactam and Nylon 6.6 is produced from hexamethylene diamine and adipic acid. Nylon 6.6 is hard to recycle, and when burnt emits harmful gases such as dioxins, nitrous oxide and hydrogen cyanide [19]-[21].

Plastic products are mostly made from feed stocks derived from crude oil and natural gas processing. While half of the fossil fuel goes into the composition of the plastic itself, the other half is combusted to provide the energy during manufacture. The amount of embodied energy and green gas emission, however, differs depending on the type of plastic products (see Table II) [18], [22].

In that sense, organic fabric seems to provide less amount of harmful gases. However, the production of organically based fabrics follows different stages that may require various energy demands depending on different specific production methods that can be employed. The main environmental impact of jute fibre is caused by the greenhouse gases that are emitted during the agricultural and industrial production of the fibre, including the negative impact of fertilizers and pesticides, that could produce the high nitrate and phosphate emissions and have negative impact on the environment. Although plants provide a positive impact regarding global warming, the energy and the gases released during the production of the fabric (mainly
$\mathrm{CO}_{2}$ and $\mathrm{CH}_{4}$ released during retting) are important in the process of calculating the embodied carbon and energy of jute fibre production according to Rafail [23] who cited ecoinvent database [24], [25].

TABLE II: EMBODIED ENERGY AND POLLUTION POTENTIAL

\begin{tabular}{ccccc}
\hline \hline Material & $\begin{array}{c}\text { Embodie } \\
\text { d Energy } \\
(\mathrm{MJ} / \mathrm{Kg})\end{array}$ & $\begin{array}{c}\text { Embodied } \\
\text { Carbon } \\
\left(\mathrm{CO}_{2} / \mathrm{Kg}\right)\end{array}$ & $\begin{array}{c}\mathrm{GWP} \\
(\mathrm{g} / \mathrm{kg})\end{array}$ & $\begin{array}{c}\mathrm{AP} \\
(\mathrm{g} / \mathrm{kg})\end{array}$ \\
\hline $\begin{array}{c}\text { Polyester } \\
\begin{array}{c}\text { Polyvinyl } \\
\text { chloride } \\
\text { (PVC) }\end{array}\end{array}$ & $77.83^{27}$ & $2.7^{22}$ & $12200^{28}$ & $21^{29,30}$ \\
Polyethylene & $83.1^{27}$ & $1.94^{27}$ & $1400^{18}$ & $13^{18}$ \\
Polyamide & $160.07^{27}$ & $5.5-6.5^{27}$ & $6700^{20}$ & $12^{18}$ \\
Jute Fibre & $30.5^{23,24}$ & $0.56^{25}$ & $794^{23}$ & $9.89^{23}$ \\
\hline \hline
\end{tabular}

Never the less, one of the gases that is more responsible for increasing the greenhouse effect is carbon dioxide, which is released from industrial manufacturing of the fossil fuels, and could pose a harmful effect on the environment if it passes a certain level. According to the United Nations' climate panel IPCC, there is a need to reduce human-caused emissions of carbon dioxide $\left(\mathrm{CO}_{2}\right)$ by about 45 percent from 2010 levels by 2030, reaching 'net zero' around 2050 [26]. Thus, the GWP (Global Warming Potential) associated with the carbon dioxide emission, AP (Acidification Potential) associated with sulphur dioxide formed through burning fossil fuels and other industrial processes, are taken into consideration in the assessment of the material air pollution impact, [18], [27]-[30].

The embodied energy and carbon of the suggested meshes was calculated depending on their weight and composition, (see Table III).

\begin{tabular}{|c|c|c|c|c|c|c|}
\hline Mesh & Composition & $\begin{array}{l}\text { Embodied Energy } \\
(\mathrm{MJ} / \mathrm{Kg})\end{array}$ & $\begin{array}{l}\text { Embodied Carbon } \\
(\mathrm{MJ} / \mathrm{Kg})\end{array}$ & $\begin{array}{l}\text { Weig-ht } \\
(\mathrm{Kg})\end{array}$ & $\begin{array}{l}\text { GWP } \\
(\mathrm{g} / \mathrm{Kg})\end{array}$ & $\begin{array}{l}\mathrm{AP} \\
(\mathrm{g} / \mathrm{Kg})\end{array}$ \\
\hline $\mathrm{PA}$ & Polyamide & 76.35 & $2.6-3.1$ & 0.477 & 3195.9 & 5.72 \\
\hline PVCPE1 & $72 \%$ PVC $-28 \%$ Polyester & 19.89 & 0.59 & 0.235 & 1039.6 & 3.6 \\
\hline PVCPE2 & $71 \%$ PVC $-29 \%$ Polyester & 26.9 & 0.79 & 0.317 & 1436.6 & 4.8 \\
\hline PVCPE3 & $65 \%$ PVC $-35 \%$ Polyester & 26.7 & 0.77 & 0.309 & 1600.6 & 4.9 \\
\hline PVCPE4 & $50 \%$ PVC $-50 \%$ Polyester & 28.4 & 0.8 & 0.314 & 2135.2 & 5.3 \\
\hline PVCPE5 & $67 \%$ PVC $-33 \%$ Polyester & 30.35 & 0.88 & 0.353 & 1752.3 & 5.5 \\
\hline PVCPE6 & $57 \%$ PVC $-43 \%$ Polyester & 29.34 & 0.84 & 0.331 & 2000.6 & 5.4 \\
\hline PVCPE7 & $58 \%$ PVC $-42 \%$ Polyester & 42.16 & 1.21 & 0.477 & 2831.5 & 7.8 \\
\hline $\mathrm{JF}$ & Jute Fabric & 4.9 & 0.09 & 0.161 & 127.8 & 1.6 \\
\hline
\end{tabular}

\section{Economic Impact}

A fog harvesting structure needs to be easy to construct and maintain, and it must be economical. As the structure and the piping costs remain constants, the changing factor was the type of the mesh used.

The different values of the meshes were obtained from the factories that produced the meshes or their official resellers, (see Table IV).

As mentioned earlier, most of the meshes are composed of Polyester with PVC, however, the difference of the economic value of each mesh could be due to the percentage of each material, the thickness of the fabric and the rate of open areas in the material.
TABLE IV: MESHES UNDER INVESTIGATION AND THEIR COSTS FROM THE

\begin{tabular}{cccccccc}
\multicolumn{7}{c}{ FACTORY } \\
\hline \hline Meshes & PVCP & PVCPE & PVCPE & PE1 & PE2 & PA & JE \\
& E1.2. & 3 & 4 & & & & \\
& 5.6 .7 & & & & & & \\
\hline Costs & 1.95 & 1.85 & 20 & 3.76 & 0.63 & 1.6 & 0.7 \\
$\left(€ / \mathrm{m}^{2}\right)$ & & & & & & & \\
& & & & & & & \\
\hline \hline
\end{tabular}

\section{Fog Collection Efficiencies $\eta\left(R^{*}, D^{*}\right)$}

Fog Collection Efficiencies $\eta\left(\mathrm{R}^{*}, \mathrm{D}^{*}\right)$ was calculated using Droplet Impact Models proposed by Langmuir and Blodgett [10] and recently by Rivera [11], [31]. (See Eq (1))

$$
\eta=\eta_{a}\left(D^{*}\right) \eta_{d}\left(R^{*}\right)=\left[\frac{s C}{1+\sqrt{C_{O} / C_{D}}}\right]\left[\frac{s t}{s t+\pi / 2}\right]
$$


where: $\eta_{a}$ is the aerodynamic collection efficiency, $\eta_{d}$ is the deposition efficiency, $S C$ is the shading coefficient, $\mathrm{C}_{0}$ is the pressure drop coefficient for a cylindrical mesh, $C_{D}$ is the drag coefficient and $S t$ is the Stokes number.

According to Park, et al. [11], Fog-harvesting efficiency $(\eta)$ is a function of the ratio of the radius $\left(R^{*}\right)$ of the fog droplets $\left(r_{f o g}\right)$ to the radius of the wire $(R)$ (see Eq (2)), and the spacing ratio of the woven mesh $\left(D^{*}\right)$, (see Eq (3)), or the shading coefficient $S C$, which could be identified as a fraction of the projected area that is occluded by the solid mesh fibers.

$$
R^{*}=r_{f o g} / R
$$

where: $R *$ is the ratio of the radius, $r_{f o g}$ is the radius of the fog droplet and $R$ is the radius of the wire, both in $\mu \mathrm{m}$.

$$
D^{*}=(R+D) / R
$$

where: $D^{*}$ is the spacing ratio of the woven mesh, and $D$ is the half spacing of the mesh, both in $\mu \mathrm{m}$.

The meshes were evaluated taking their thickness in regards, specifying the fabric radius, $2 R=$ thickness of the mesh. The shading coefficient of the meshes was calculated depending on the open areas ratio of each mesh. As the shading coefficient represents the area of the fabric of the mesh, the open areas ratio represents the area of openings in relation to the whole area of the mesh (see Eq (4)).

$$
S C=100-o p
$$

where: $S C$ is the shading coefficient and $o p$ is the open area ratio.

Due to the variability of the spacing's size and location (D) on some of the analyzed meshes, the evaluation of the fog harvesting efficiency was carried on as a function of the ratio of the radius $\left(R^{*}\right)$ and $(S C)$ which was calculated based on Eq (4).

Assuming a wind velocity of $2 \mathrm{~m} / \mathrm{s}$ and uniform droplet size $\left(r f_{o g} \simeq 3 \mu \mathrm{m}\right)$ [11] calculations took place depending on the meshes physical properties (see Fig. 2).

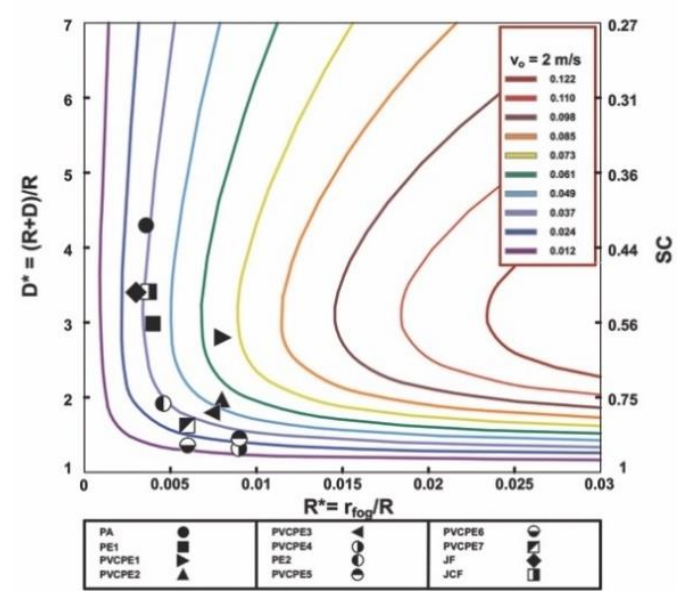

Fig. 2. Contour map in $R^{*}, D^{*}$ and $S C$, assuming a wind velocity of $2 \mathrm{~m} / \mathrm{s}$ and uniform droplet size $r_{f o g} \simeq 3 \mu \mathrm{m}$.

The results show the meshes with a smaller radius to be more efficient than other meshes, though, not disregarding the effect of the open area, as the meshes with higher open areas ratio, and thus smaller SC, proved to have a higher efficiency when compared to a mesh with similar thickness. However, with open areas ratio could reach a point where most fog droplets pass through the open area between wires without being deposited into the mesh, thus affecting its collecting efficiency. PVCPE1 $\boldsymbol{\nabla}$, PVCPE2 $\boldsymbol{\Delta}$ and PVCPE3 4 presented the highest efficiency ranging between $4.9 \%$ to $7.3 \%$.

\section{SECOND APPROACH}

The laboratory tests in the selected meshes were performed in controlled environment in the Textile Engineering Department and in the Polymers Engineering Department laboratories at University of Minho. The tests analyzed the meshes composition and permeability for water vapor and air and provided information about their main physical characteristics, such as composition, weight and thickness. On-site tests are now under development.

\section{A. Weight Tests}

According to ASTM 2007 and ISO 2286-2 [32], [33], the determination of the weight of a certain fabric, the mass per unit area or GSM gram per square meter, was measured by cutting specimen and placing them on electric balance. In the present case, 5 specimens were cut manually from each mesh, with the dimension of $10 \mathrm{~cm} \times 10 \mathrm{~cm}$. For the weighing process, an ISO approved precision balance was used KERN 770 , where each sample was placed on the weighing pan to determine the weight (see Fig. 3).

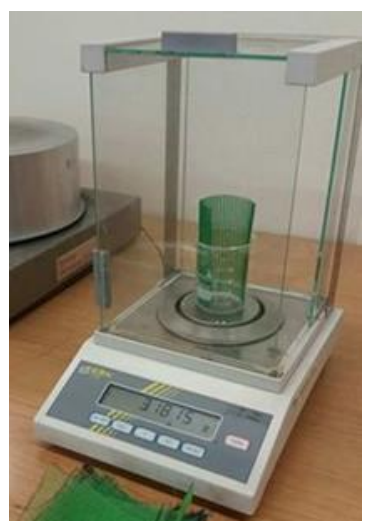

Fig. 3. The sampling and weighing process using GSM method of measurement.

After that, the average weight of each mesh is determined based on the weight of its ten samples and the average weight was converted from $\mathrm{g} / 100 \mathrm{~cm}^{2}$ to $\mathrm{g} / 1 \mathrm{~m}^{2}$

\section{B. Air Permeability Test}

Air permeability tester FX3300 was used to evaluate the air permeability of the meshes. This device is a powerful muffled vacuum pump that draws air through an interchangeable test head with a circular opening, (see Fig. 4).

Ten specimens from each fabric were prepared, and the selected test fabric was mounted on the instrument. The specimen was clamped over the test head opening by pulling down the clamping arm which automatically start the 
machine. The standard test pressure which equals $200 \mathrm{~Pa}$ is maintained automatically through the procedure and an area of $20 \mathrm{~cm}^{2}$ was tested for each sample in accordance with (ISO 9237) [34], after a few seconds the air permeability of the tested specimen was digitally displayed with the pre-selected measuring units, which is $1 / \mathrm{m}^{2} / \mathrm{s}$. The results then were collected and the average air permeability for each mesh was calculated.

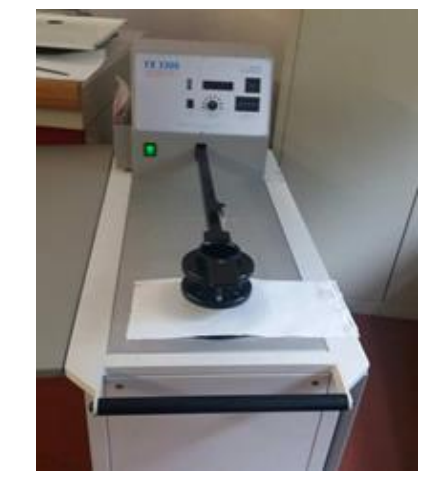

Fig. 4. Air Permeability tester FX 3300.

\section{Water Vapor Permeability Test}

The used method of testing was the cup method for water vapor permeability tests. According to ISO 8096 and BS 7209 [35], [36] the test specimen was tested along with a specified reference fabric, and from that the ratio of their water vapor permeability was calculated using a M261 revolving 8 cups water transmission tester [37].

The standard fabric was mostly made of monofilament high tenacity woven polyester yarn and in each test a new sample of the standard fabric was prepared. In order to be able to test the fabrics for water vapor permeability the specimens were cut to fit above the testing cups, and two specimens from three meshes were tested in each 24-hour procedure. As each procedure took place, the cups were filled with a distilled water, and the test specimen and the reference specimen were sealed over the open mouth of testing cups with a covering ring of a similar diameter of the cup, however, before adding the specimen a rectangular support was added to prevent the sagging of the fabric. The quantity of water inside each cup was about $46 \mathrm{ml}$ and was adjusted to maintain a still air of almost $10 \pm 1 \mathrm{~mm}$ between the specimen and the surface of the water. The ring was then furtherly connected to the cup by an adhesive tape to prevent to provide accurate results. After that the tested cups were assembled on a rotating turntable. The M621 then is turned on and the turntable is rotated on a slow rate to avoid forming a still air above the tested samples. The test specimen along with the cups were weighed after 1 hour using KERN EG precision balance, to equilibrate the water declination. The cups were then placed again on the turntable and the machine was turned on again for $24 \mathrm{~h}$, after this period the cups were reweighted (see Fig. 5).
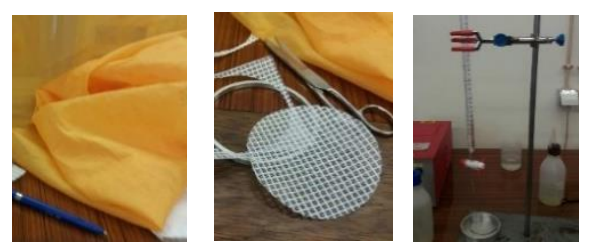
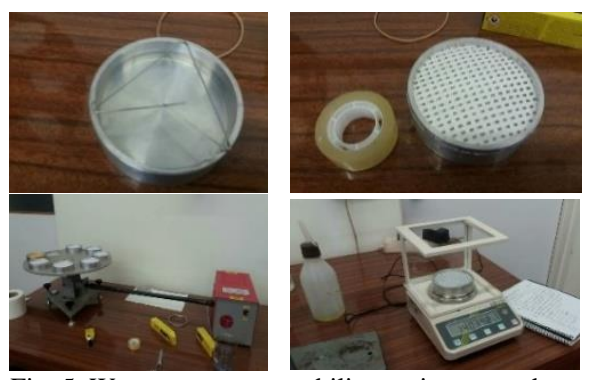

Fig. 5. Water vapor permeability testing procedure.

From the loss of weight between the two weighing the ratio of water vapor permeability $(W V P)$ was obtained, (see $\mathrm{Eq}(5), \mathrm{Eq}(6))$.

$$
\text { WVP in }\left(g / m^{\wedge} 2\right) / \text { day }=24 M / A t
$$

where: $M$ is the loss of mass in $\mathrm{g}$ of assembly in time $t(\mathrm{~h})$, and $A$ is the area of the tested sample in $\mathrm{m}^{2}$.

$$
I=\left\{(W V P)_{-} f /(W V P)_{-} r\right\} \times 100
$$

where: $I$ is the ratio of water vapor permeability, $(W V P) \_f$ is the mean permeability of the tested samples, and $(W V P) \_r$ is the mean permeability of the reference fabric.

\section{Thickness Test}

Ten samples had been prepared for this test in accordance with ISO 5084 [38]. The specimens had a dimension of 10 $\mathrm{cm} \times 10 \mathrm{~cm}$. A digital thickness gauge meter M034A is used for this test, where the thickness of a specimen is measured as the distance between the reference plate in which the sample is located and a parallel circular presser foot that apply a specified pressure on the area of the textile being tested.

In the purpose of starting the measurements, the presser foot and the reference plate were cleaned, then, the presser foot movement was checked. The connected computer with the associated software was turned on and set to follow the standard of ISO 5084, where the area of the specimen subjected to the presser foot was set to $19.625 \mathrm{~cm}^{2}$ and a standard pressure of $100 \mathrm{~Pa}$ was added. After that, a new measurement process was launched.

In the purpose of calibrating the machine, the presser foot was loaded to exert an appropriate of $19.6 \mathrm{~g}$ on the reference plate and the thickness gauge is set to read zero. The presser foot then was raised and a new test was required, where a specimen was placed on the reference plate and the load was set to zero on the software. After that, the presser foot was loaded, and the thickness of the tested sample was displayed by the software after reaching a load that ranges between 19.6 and $21 \mathrm{~g}$. The thickness value could either be accepted or refused. Ten samples of each material were tested and the average weight was calculated (see Fig. 6). It must be mentioned that a new process of measurement must be launched for each fabric.

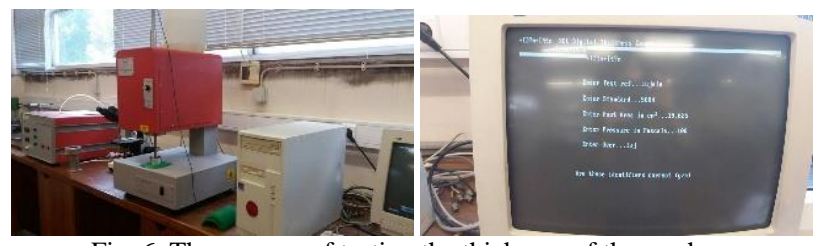

Fig. 6. The process of testing the thickness of the meshes. 


\section{E. Open Areas Test}

An image analysis technique was used in this case, using Leica Application Suite (LAS) V4.4, which assimilate Leica automated microscopes and digital cameras with a computer software used to analyze captured images [39]. The aim of this process was to use image processing analysis to calculate the surface and open areas ratio of the mesh. It must be noted, that the illumination of the microscope is adjusted in accordance with Köhler Illumination technique [40], which is a method of providing the optimum specimen illumination that use transmitted and reflected light to provide high-quality images. The process included image modeling where 2 samples of each mesh were used, the samples were placed as flat as possible under the microscope with a white or black background in accordance with the mesh color. The illumination of the microscope was then turned on and was adjusted and the resolution of the image was adjusted. On the software, the image format and exposure was adjusted to increase contrast between the fabric and the background, the images were acquired, and a scale bar was added, (see Fig. 7).
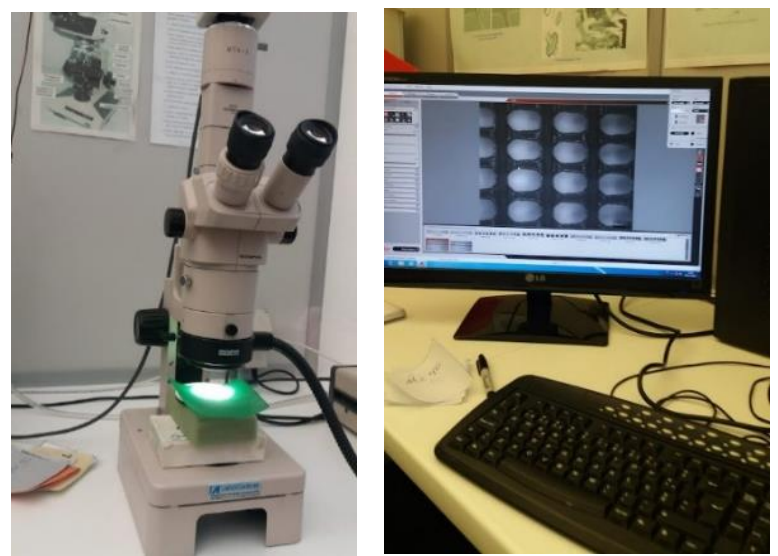

Fig. 7. Meshes images acquiring process

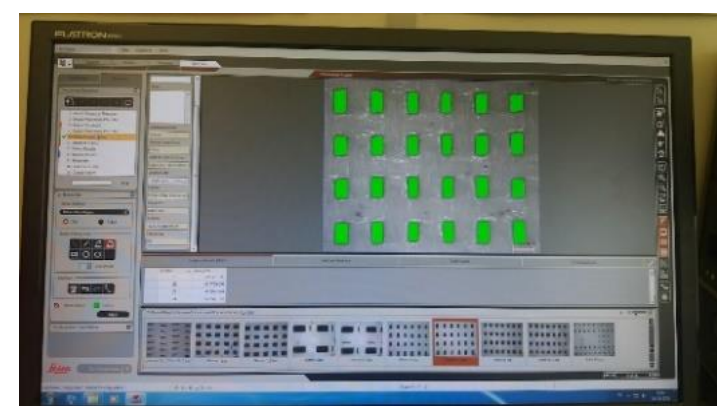

Fig. 8. Image analysis process using LAS software.

After that, the images were browsed, processed and analyzed. The browse stage allows to view the stored images under various zoom, and to navigate within a zoomed image. The process stage includes two features; enhance and annotate, which allow for making adjustments including the contrast and the colors of the taken photo, followed by analysis which either could be interactive or automatic depending on the fabric spaces and openings regularity. The analysis involves various steps, mainly: threshold adjustment of open and fabric areas, Binary image editing where measured areas are edited, measure frame where the frame type is selected mostly to include the entire image in our case pixel size of the image was $1280 \times 1024 \times 24 \mathrm{bpp}$, and results were displayed depending on the study requirements, followed by measurements. Eventually, a LAS image analysis report was created which is mostly an excel file that includes the results, statistics, images of the studied samples (see Fig. 8).

\section{F. Chemical Composition Analysis}

Chemical composition test was performed by the chemical laboratory in the textile department and Differential Scanning Calorimetry (DSC) method was used for the purpose of identifying the materials. DSC is a technique that measures the difference between heat flow rates into a sample and a reference material while subjected to controlled temperature [41]. One of this method applications is identifying unknown material. The test involved taking small samples from the meshes and subjecting it to certain temperature levels in the purpose of identifying the material through its reaction to the heat. However, the results had shown that the most of the meshes are coated and other test need to be done. Following the results of the previous test, the manuals of some meshes were obtained from the factories to identify their composition, whereas the meshes that lacked any reference (PE1 and PE2), were prepared to be tested again using the FT-IR method which stands for Fourier Transform InfraRed, in which the samples were subjected to IR radiation and the samples absorbance of infrared radiation at numerous wavelengths to verify the structure and molecular composition of the material [42] (see Fig. 9). The results were then analyzed and the composition of the meshes was determined.

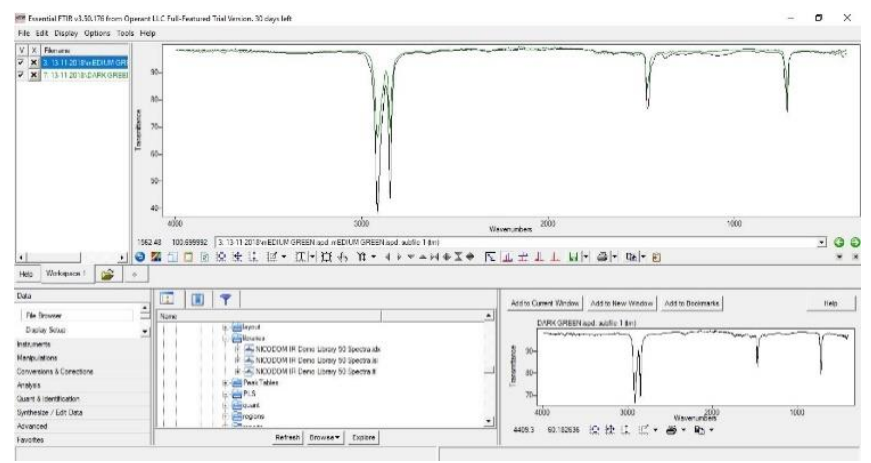

Fig. 9. FT-IR material analysis results

The results of the tests are as the following (see Table V).

Table $\mathrm{V}$ shows two types of meshes under assessment: organic and synthetic meshes. The organic meshes are woven jute and coated jute with a heat applied coating performed in the Chemistry Lab in the Textile Engineering Department at University of Minho. Coating treatment was attempted to be applied on the analyzed meshes. However, due to the high temperatures, reaching around $170^{\circ} \mathrm{C}$ during the coating, the synthetic meshes suffered deformation that affected the measurement process, promoting the necessity of applying unheated treatment.

Furthermore, the meshes with higher air permeability were found to have higher open areas ratio, whereas most of the meshes with high WVP ratio were also found to have higher open areas ratio. The meshes selected for the on-site tests were those that present high air and water vapour permeability, and at the same time, had high open areas ratio, see Fig. 10. 
TABLE V: LABORATORY TESTS RESULTS ON THE SELECTED MESHES

\begin{tabular}{|c|c|c|c|c|c|c|}
\hline Meshes & Composition & $\begin{array}{l}\text { Water Vapor } \\
\text { Permeability } \\
\text { (WVP) ratio }\end{array}$ & $\begin{array}{l}\text { Air Permeability } \\
\qquad\left(1 / \mathrm{m}^{2} / \mathrm{s}\right)\end{array}$ & $\begin{array}{l}\text { Weight } \\
\left(\mathrm{g} / \mathrm{m}^{2}\right)\end{array}$ & $\begin{array}{l}\text { Thickness } \\
\text { (mm) }\end{array}$ & $\begin{array}{l}\text { Open areas } \\
\text { ratio }\end{array}$ \\
\hline $\mathrm{PA}^{(\mathrm{a})}$ & Polyamide & $92.23 \%$ & N/A & 477 & 1.68 & $59.91 \%$ \\
\hline PE1* (b) & Polyethylene & $97.5 \%$ & 8805 & 305 & 1.56 & $43.89 \%$ \\
\hline $\mathrm{PVCPE}^{(\mathrm{c})^{-1}}$ & $72 \%$ PVC $-28 \%$ Polyester & $93.92 \%$ & 6784 & 235 & 0.78 & $40.55 \%$ \\
\hline PVCPE2 ${ }^{(\mathrm{d})}$ & $71 \%$ PVC $-29 \%$ Polyester & $91.26 \%$ & 3194 & 317 & 0.77 & $22.92 \%$ \\
\hline PVCPE3 $^{(\mathrm{e})}$ & $65 \%$ PVC $-35 \%$ Polyester & $85.57 \%$ & 3475 & 309 & 0.90 & $20.96 \%$ \\
\hline PVCPE4 ${ }^{(f)}$ & $50 \%$ PVC $-50 \%$ Polyester & $84.95 \%$ & 1175 & 314 & 0.64 & $7.54 \%$ \\
\hline PE2* (g) & Polyethylene & $83.39 \%$ & 2889 & 64 & 1.31 & $23.47 \%$ \\
\hline PVCPE5 & $67 \%$ PVC $-33 \%$ Polyester & $82.93 \%$ & 1707 & 353 & 0.67 & $11.85 \%$ \\
\hline PVCPE6 & $57 \%$ PVC $-43 \%$ Polyester & $79.72 \%$ & 1210 & 331 & 1.00 & $7.63 \%$ \\
\hline PVCPE7 ${ }^{(j)}$ & $58 \%$ PVC $-42 \%$ Polyester & $75.96 \%$ & 1813 & 477 & 1.00 & $14.09 \%$ \\
\hline $\mathrm{JF}^{(\mathrm{k})}$ & Jute & $87.69 \%$ & 8144 & 161 & 1.91 & $49.2 \%$ \\
\hline $\mathrm{JCF}^{(1)}$ & Jute Coated with Baygard & $86.98 \%$ & 7587 & 161 & 1.74 & $49.3 \%$ \\
\hline
\end{tabular}

*Meshes tested on site and in the laboratory

(a) Nylon shading mesh; (b) Plastic Green mesh; (c) Print MS25 (Endutex); (d) Print MS40 (Endutex ); (e) Print RC3 (Endutex); (f) SunWorker (Dickson solar protection ); (g) Black Shading mesh; (h) Print MS55 (Endutex); (i) Print MS74 (Endutex); (j) Print MP90 (Endutex); (k) Jute; (l) Coated Jute.

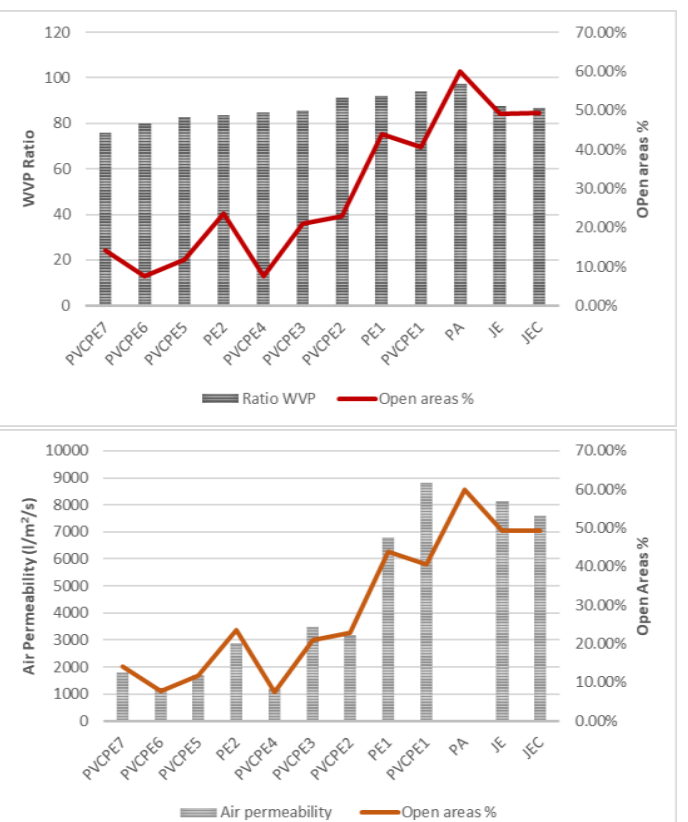

Fig. 10. Ratio between meshes open areas and their water vapor and air permeability.

\section{RESULTS AND DISCUSSION}

In regards to the laboratory results, the meshes ability to provide higher water vapor permeability and air permeability are connected to their opening areas ratio, and the on-site results are showing that three of the so far four tested meshes are able to retain water from fog, namely PA, PVCPE1 and PE1 meshes. The physical characteristics of those meshes were considered in the decision to evaluate them on-site, where they could show that the ability to retain water is related to their open areas ratio and water vapor and air permeability.

However, although the meshes retained water, they were unable to drain it down to the collector, so it is now under evaluation the use of an affordable hydrophobic coating material to treat the hydrophilic surface of the meshes. In K. Satiye and K. Afsin review on different fog harvesting technologies that adopted hydrophobic surfaces for fog harvesting, it was noted that in many cases the focus was on the addition of hydrophilic material to the hydrophobic surfaces to improve the collection efficiency. Although successful and informing, it was also noted by these authors that the development of such structures in the aim of achieving an efficient system included the production of different materials that required costly treatments [43]. Thus, it must be noted that fog harvesting technique is based on the principle of providing a cheap source of clean water, and while developing a functional system is important, the priority should be on providing a locally available cheaper material where the environmental, social and economic aspects are compatible (see Table VI).

TABLE VI: Result of the Meshes Environmental Analysis

\begin{tabular}{|c|c|c|c|c|c|c|c|}
\hline Meshes & \multicolumn{2}{|c|}{ 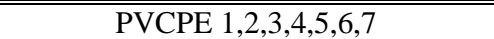 } & PA & PE1,2 & JF & & JCF \\
\hline Composition & Polyester & PVC & Polyamide & Polyethylene & Jute Fabric & Jute Fiber & Baygard Coating \\
\hline Noise pollution & $\begin{array}{c}\text { Alone, } \\
\text { psychological } \\
\text { effect of reducing } \\
\text { noise sensitivity. }\end{array}$ & $\begin{array}{l}\text { Enhance the ability } \\
\text { to reduce noise at } \\
\text { low and medium } \\
\text { frequencies }\end{array}$ & $\begin{array}{c}\text { Alone, } \\
\text { psychological } \\
\text { effect of reducing } \\
\text { noise sensitivity. }\end{array}$ & $\begin{array}{c}\text { Alone, } \\
\text { psychological } \\
\text { effect of reducing } \\
\text { noise sensitivity. }\end{array}$ & Alone, psyc & $\begin{array}{l}\text { logical effe } \\
\text { sensitivi }\end{array}$ & of reducing noise \\
\hline Air pollution & $\begin{array}{l}\text { As a fog } \\
\text { harvesting mesh, it } \\
\text { captures toxins } \\
\text { attached to fog. } \\
\text { However, } \\
\text { Polyester emits } \\
\mathrm{C}_{8} \mathrm{H}_{8} \text { and } \mathrm{CH}_{2} \mathrm{Cl}_{2} \\
\text { produced. } \\
\text { If burnt, it emits } \\
\mathrm{CO}, \mathrm{CO} 2, \mathrm{C}_{6} \mathrm{H}_{6} \\
\mathrm{C}_{8} \mathrm{H}_{8}, \mathrm{CH}_{2} \mathrm{O} \text {. }\end{array}$ & $\begin{array}{l}\text { As a fog harvesting } \\
\text { mesh, it captures } \\
\text { toxins attached to } \\
\text { fog. } \\
\text { PVC production } \\
\text { emits } \mathrm{Cl}_{2}, \mathrm{C}_{2} \mathrm{H}_{4} \text {, } \\
\text { dioxin, } \mathrm{C}_{2} \mathrm{H}_{3} \mathrm{Cl} \text {, } \\
\text { dichloretane, } \mathrm{Hg} \text { and } \\
\text { other damaging } \\
\text { substances. } \\
\text { If burnt, emits } \mathrm{HCl} \text {, } \\
\text { dioxin, } \mathrm{CO}, \mathrm{CO}_{2}, \\
\mathrm{CH}_{4}, \mathrm{Ba} \text { and } \mathrm{Cd} \text {. }\end{array}$ & $\begin{array}{l}\text { As a fog } \\
\text { harvesting mesh, } \\
\text { it captures toxins } \\
\text { attached to fog. } \\
\text { PA Production } \\
\text { emits } \mathrm{CO}_{2}, \mathrm{~N}_{2} \mathrm{O} \text {, } \\
\mathrm{SO}_{2} \text { and } \mathrm{CH}_{4} \\
\text { If burnt, it emits } \\
\text { dioxins, } \mathrm{N}_{2} \mathrm{O} \text { and } \\
\mathrm{HCN} \text {. }\end{array}$ & $\begin{array}{l}\text { Some products } \\
\text { have high ability to } \\
\text { collect water from } \\
\text { fog, thus, as a result } \\
\text { collect toxins } \\
\text { attached to the fog. } \\
\text { If burnt, it doesn't } \\
\text { emit harmful gases }\end{array}$ & $\begin{array}{r}\text { If function } \\
\text { the ability } \\
\text { Jute produc }\end{array}$ & $\begin{array}{l}\text { as a fog har } \\
\text { collect toxi } \\
\text { from the } \\
\text { on and dispe } \\
\text { ount of harm }\end{array}$ & $\begin{array}{l}\text { s attached to fog } \\
\text { ir. } \\
\text { al emit minimum } \\
\text { ul gases }\end{array}$ \\
\hline
\end{tabular}




\begin{tabular}{|c|c|c|c|c|c|c|}
\hline Thermal & \multicolumn{6}{|c|}{ Provides shading. However, that depends on the open area ratio or shading coefficient and type of material } \\
\hline $\begin{array}{c}\text { Economical } \\
\text { properties } \\
\left(€ / \mathrm{m}^{2}\right)\end{array}$ & \multicolumn{2}{|c|}{ Between 1.85 to 20} & 1.60 & 0.63 to 3.76 & \multicolumn{2}{|c|}{0.72} \\
\hline $\begin{array}{c}\text { Embodied } \\
\text { Energy }(\mathrm{MJ} / \mathrm{kg})\end{array}$ & 103.83 & 77.2 & 160.07 & 83.1 & \multicolumn{2}{|c|}{30.5} \\
\hline $\begin{array}{c}\text { Embodied } \\
\text { Carbon } \\
\left(\mathrm{Co}_{2} / \mathrm{kg}\right)\end{array}$ & 2.7 & 2.41 & 5.5 to 6.5 & 1.94 & \multicolumn{2}{|c|}{0.56} \\
\hline $\mathrm{GWP}(\mathrm{g} / \mathrm{kg})$ & 12200 & 1400 & 6700 & 751 & \multicolumn{2}{|c|}{0.79} \\
\hline $\mathrm{AP}(\mathrm{g} / \mathrm{kg})$ & 21 & 13 & 12 & 9 & \multicolumn{2}{|c|}{0.0098} \\
\hline Weight $\left(\mathrm{g} / \mathrm{m}^{2}\right)$ & \multicolumn{2}{|c|}{220 to 530} & 477 & 64 to 305 & 161 & 161 \\
\hline $\begin{array}{l}\text { Thickness } \\
\text { (mm) }\end{array}$ & \multicolumn{2}{|c|}{0.60 to 1} & 1.68 & $1.31-1.56$ & 1.91 & 1.74 \\
\hline
\end{tabular}

\section{CONClusions And Further Research}

Although jute meshes appear to have lower Fog Collection Efficiencies $\eta$ than other studied meshes such as PVCPE1, 2 and 3, they present significantly lower levels of embodied carbon and embodied energy, compared to most of the other meshes, and are more effective regarding the coating options. Meshes such as PVCPE1, 2 and 3 present similar embodied energy levels to the PE 1 mesh, and higher possibility of functioning as a fog harvesting mesh, thus providing an alternative without the anticipated environmental damage linked to the production of the material. However, it must be noted that PVCPE1, 2 and 3 meshes, offer a high GWP and AP potential compared to JF meshes and to PE1 and PE2 meshes. On the other hand, although PA mesh proved to be functional in retaining water, it must be taken into consideration the high levels of embodied energy and embodied carbon associated with the mesh production and the high levels of GWP and AP compared to the rest of the meshes. PVCPE meshes have the advantage of providing more options for shading in comparison with the ability of the $\mathrm{JF}$, JCF and PE meshes, as some of them were designed for shading purposes. On the other hand, polyester, PVC and Nylon (polyamide) production processes and burning may emit some harmful gases to the environment if not treated properly, whereas meshes composed of polyethylene are not known to emit a high concentration of harmful gasses if burnt, and organic meshes seem to provide the most environmental option with limited environmental impacts despite their lower Fog Collection Efficiency $\eta$.

In the process of deciding which mesh to apply on a structure, the functionality and the environmental profile of the mesh is important as jute meshes have lower environmental impact, followed by polyethylene meshes, which proved to be functional in some cases, i.e. PE1. Nonetheless, it is possible to use other meshes that may have a higher economic and harmful environmental impact, if not treated properly, but could capture water and provide some positive environmental benefits, taking into consideration their physical characteristics.

\section{CONFLICT OF INTEREST}

The authors declare no conflict of interest.

\section{AUTHOR CONTRIBUTIONS}

L. Hadba conducted the research and tests, and wrote the paper, P. Mendonça, L.T. Silva and M. A. Carvalho reviewed, edited, and analyzed the paper; all authors had approved the final version.

\section{ACKNOWLEDGMENT}

The project is developed with the support of the Architecture school.

\section{REFERENCES}

[1] Drinking-Water, WHO, World Health Organization, Geneva, June 2019.

[2] T. E. Mull, HVAC Principles and Applications Manual, McGraw-Hill Companies, New York, 1997.

[3] A. Gloda, R. E. Guasp, and A. A. Baladón, "Fog collectors in tropical areas," in Proc. the International Symposium on Precipitation and Evaporation, vol. 3, pp. 273-278, September 1993.

[4] M. S. Nelson-Esch, Mist As an Economical Source of Potable Water, Benoni: Solar Utilities Ltd.

[5] H. Xie, H.-X. Huang, and H.-Y. Mi. "Gradient wetting state for droplet transportation and efficient fog harvest on nanopillared cicada wing surface," Materials Letters, vol. 221, pp. 123-127, June 2018.

[6] R. S. Schemenauer and P. Cereceda, "A proposed standard fog collector for use in high-elevation regions," Journal of Applied Meteorology, vol. 33, pp. 1313-1322, October 1994.

[7] WARKA WATER. (2017). [Online]. Available: http://www.warkawater.org/project/

[8] J. Olivier, "Fog-water harvesting along the West Coast of South Africa: A feasibility study," Water SA, vol. 28, no. 4, pp. 349-360, 2002.

[9] R. S. Schemenauer, P. Cereceda, and P. Osses, FogQuest: Sustainable Water Solutions, Toronto, 2005.

[10] I. Langmuir and K. Blodgett, A Mathematical Investigation of Water Droplet Trajectories, Illinois: Army Air Forces Headquarters, Air Technical Service Command, 1946.

[11] K.-C. Park, S. S. Chhatre, S. Srinivasan, R. E. Cohen, and G. H McKinley, "Optimal design of permeable fiber network structures for fog harvesting," Langmuir, vol. 29, no. 43, pp. 1-36. October 2013.

[12] S. Basu, A. K. Agarwal, A. Mukhopadhyay, and C. Patel, Droplet and Spray Transport: Paradigms and Applications, Singapore: Springer, 2017.

[13] I. D. Vilder, G. Buyle, and V. Virgo, "Materials for shade nets," Speedkits, 2015.

[14] C. D. Ritchie, W. Richards, and P. A. Arp, "Mercury in fog on the Bay of Fundy (Canada)," Atmospheric Environment, vol. 40, no. 33, pp. 6321-6328, October 2006.

[15] K. T. Valsaraj et al., "Fog chemistry in the Texas-Louisiana Gulf Coast corridor," Atmospheric Environment, vol. 42, no. 9, pp. 2048-2061, March 2008

[16] J.-H. Lin et al., "Manufacture and properties of protective sound-absorbing mesh-reinforced composite foam board: Effects of filler content and mesh opening," Fibers and Polymers, vol. 16, no. 9, pp. 2046-2055, October 2015.

[17] H. S. Seddeq, "Factors Influencing Acoustic Performance of Sound Absorptive Materials," Australian Journal of Basic and Applied Sciences, vol. 3, no. 4, pp. 4610-4617, 2009.

[18] B. Berge, The Ecology of Building Materials, Woburn: Architectural Press, 2000, sec.1-2.

[19] Eco-profiles and Environmental Product Declarations of the European Plastics Manufacturers: Polyamide 6.6 (PA6.6), PlasticsEurope, Brussels, 2014.

[20] Eco-profiles and Environmental Product Declarations of the European Plastics Manufacturers: Polyamide 6 (PA6), PlasticsEurope, Brussels, 2014. 
[21] S. S. Muthu, Assessing the Environmental Impact of Textiles and the Clothing Supply Chain, Cambridge: Woodhead Publishing, 2014, ch. 1 p. 14.

[22] EcoInvent Data v2.2, Ecoinvent reports No. 1-25. EIC, (EcoInvent Centre), Switzerland, Duebendorf: Swiss Centre for Life Cycle Inventories, 2010.

[23] R. Gkaidatzis, "Bio-based FRP structures: A pedestrian bridge in Schiphol Logistics Park," Master thesis. Dept. Building Technology, Delft Univ., Delft, Netherlands, 2014.

[24] R. Frischknecht, N. Jungbluth, H. J. Althaus, G. Doka, R. Dones, T. Heck, S. Hellweg, R. Hischier, T. Nemecek, G. Rebitzer, and M. Spielmann, "The ecoinvent database: Overview and methodological framework," International Journal of Life Cycle Assessment, vol. 10, pp. 3-9, January 2005.

[25] A. K. Singh, K. Mukesh, and S. Mitra, "Carbon footprint and energy use in jute and allied fibre production," Indian Journal of Argicultural Sciences, vol. 88, no. 8, pp 1305-1316. August 2018.

[26] Policymakers of IPCC Special Report on Global Warming of $1.5^{\circ} \mathrm{C}$ Approved by Governments, Special Report, IPCC: The Intergovernmental Panel on Climate Change, Geneva, 2018.

[27] Geoffrey Hammond and Craig Jones, Inventory of Carbon and Energy, Bath: University of Bath, 2008.

[28] Assessment of global warming potential of two textile services, ESTA Report, Suceava: EcoForum, April 2015.

[29] E. M. Kalliala and P. Nousiainen, "Life cycle assessment environmental profile of cotton and polyester-cotton fabrics," AUTEX Research Journal, vol. 1, no. 1, pp. 8-20, 1999.

[30] L. Shen and M. K. Patel, "Life cycle assessment of man-made cellulose fibres," Lenzinger Berichte, vol. 88, pp. 1-59, January 2010.

[31] J. D. D. Rivera, "Aerodynamic collection efficiency of fog water collectors," Atmospheric Research, vol. 102, no. 3, pp. 335-342. November 2011.

[32] ASTM D3776 - 07: Standard Test Methods for Mass Per Unit Area (Weight) of Fabric, ASTM International, West Conshohocken, PA, 2007.

[33] ISO 2286-2. Rubber- or plastics-coated fabrics - Determination of roll characteristics - Part 2: Methods for determination of total mass per unit area, mass per unit area of coating and mass per unit area of substrate, International Organization for Standardization, Geneva, 1998.

[34] ISO 9237. Textiles - Determination of the permeability of fabrics to air, International Organization for Standardization, Geneva, 1995.

[35] ISO 8096. Rubber- or plastics-coated fabrics for water-resistant clothing - Specification, International Organization for Standardization, Geneva, 2005.

[36] BS 7209, "Specification for water vapor permeable apparel fabrics," British Standards Institution, BSI Group, 1990.

[37] A. K. Sen, Coated Textiles: Principles and Applications, Boca Raton: Taylor \& Francis Group, 2001, ch. 9, p. 214.

[38] ISO 5084. Textiles - Determination of Thickness of Textiles and Textile Products, International Organization for Standardization, Geneva, 1996.

[39] Lieca Microsystems. (2006). Leica Application Suite. [Online]. Available: https://www.leica-microsystems.com/

[40] M. Abramowitz and M. W. Davidson, "Köhler illumination," Olympus Corporation Web Site, 2019.

[41] T. Lever, P. Haines et al., "ICTAC nomenclature of thermal analysis," Pure and Applied Chemistry, vol. 86, no. 4, March 2014.

[42] J. Bergström, "Experimental characterization techniques," Mechanics of Solid Polymers: Theory and Computational Modeling, William Andrew, 2015.

[43] S. Korkmaz and A. Kariper, "Fog harvesting against water shortage," Environmental Chemistry Letters, vol. 18, pp. 361-375, March 2020.

Copyright $\odot 2020$ by the authors. This is an open access article distributed under the Creative Commons Attribution License which permits unrestricted use, distribution, and reproduction in any medium, provided the original work is properly cited (CC BY 4.0).

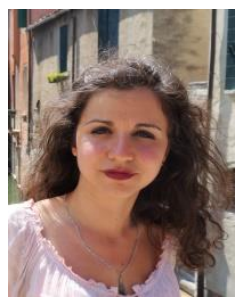

Lujain Hadba was born in Lattakia on September 2, 1989. She received her bachelor in architecture from the university of Damascus, then received her master's degree in urban engineering with the University of Minho, with the thesis: "Noise mapping of an urban Area: case study old city of Damascus, Syria". With a master's scholarship from Erasmus Mundus. She is a PhD student of the Architecture School of the University of Minho, Portugal. She is presently developing a $\mathrm{PhD}$ thesis titled: "functional conditioning systems for urban environments". It aims toward the development of functional conditioning solutions that take the maintains of the ecosystem as a priority, and that considers a lot of suggested solutions around the world as a reference. The main research subjects involve green infrastructure, development of sustainable projects and promote new techniques of building in urban areas.

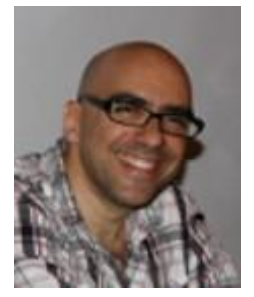

Paulo Mendonça was born in Porto on $10^{\text {th }}$ June 1969. He got the $\mathrm{PhD}$ in civil engineering by the University of Minho, with the thesis: "Living under a second skin", acclaimed by unanimity (2005) with a $\mathrm{PhD}$ fellowship from FCT (Portuguese Foundation for Science and Technology). He was a JNICT (former FCT) fellowship student in the Textile Engineer Department of the University of Minho, where he obtained the MSc Degree defending a thesis about "Smart Textiles in Architecture" (1997). He Graduated in Architecture by the University of Porto, Portugal (1994). He was Erasmus granted student in ETSAB, Barcelona (1993-1994).

$\mathrm{He}$ is associate professor in the Architecture School of the University of Minho, Portugal (EAUM). He was coordinator of Detech Research Group (2015-2018) president of EAUM (2011-2012) and vice-president (2010-2011). Architectural Graduate and Integrated Master Studies Director (2005-2009). Author of more than 150 publications. His research is in six concluded research projects. Since 1995, during his MSc thesis he started in the specialization field of "Lightweight Constructions", progressively devoting his research interests to the area of Building Physics and Sustainability. The main research subjects includes lightweight and mixed weight buildings, low cost housing, local and global economic asymmetries, low-tech strategies, energy costs and sustainable development, new materials and technologies for building construction.

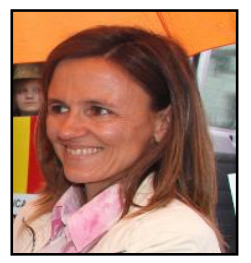

Lígia Torres Silva is an assistant professor of Civil Engineering Department, Engineering School, University of Minho, Portugal (UM). She got the PhD in civil engineering by the University of Minho, with the thesis: "Evaluation of urban environmental quality", acclaimed by unanimity (2008). Since 2005 , during his $\mathrm{PhD}$ thesis she started in the specialization field of "noise and air pollution modelling", progressively dedicating her research interests to the area of Urban Environment Quality. In 2002, at UM, she started his regular work as a lecturer and researcher. Since then she published more than 100 scientific papers in reviewed journals or presented at international conferences Supervisor of $5 \mathrm{PhD}$ thesis and $30 \mathrm{MSc}$ thesis. Since 2001 she is an Independent Expert of Air Pollution and Urban Noise WG (within Healthy Cities European Network). Since 2013 she is an Expert Group Member of UN-HABITAT World Secretariat of City Prosperity Index. Since 2015 she is a Member of the sub-commissions SC3 - Environmental Acoustics, for standardization in environmental acoustics, in tight connection with CEN and ISO groups. Since 2016 she is a Member of the Editorial Board of International Journal of Energy and Water Resources (IJEWR). Since 2017 she is Member of International Geographical Union's Commission on Health and Environment - IGU CHE. Since 2018 member of Specialized Council for the Sustainable Development Plan - Guimarães 2030. The main research subjects includes urban environmental management with targeted goals, in particular for the management of urban air quality, for assessment and management of environmental noise and air quality.

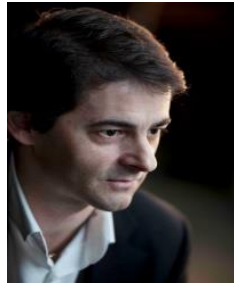

Miguel Carvalho was born in Braga on $24^{\text {th }}$ November 1968. He got the $\mathrm{PhD}$ in textile engineering by the University of Minho (2003). He obtained the MSc degree defending a thesis about "Sewing Dynamics" (1996). He graduated in textile engineering by the University of Minho, Portugal (1991)

$\mathrm{He}$ is auxiliary professor in the School of Engineering of the University of Minho, Portugal (EEUM). He was visiting professor at MIT (2011); visiting professor at Cornell University (2017); visiting professor at Riga Technical University (2019). Author of more than 150 publications, result of more than 20 projects, most involving Industry, resulting in 7 international patents and 2 brands (Weadapt and FYT Jeans). The main research subjects include sewing dynamics, clothing design, textile design, pattern design, anthropometrics, ergonomics and development of functional/multi-functional materials and textile products and interactive textiles (electronic textiles) with applications in the health, automobile, sport and other sectors. He is founder and head of R\&D of the Spin-off enterprise from University of Minho, Weadapt Inclusive Design and Engineering Solutions since November 2008. 